\title{
Mating Patterns, Mate Choice, and Birth Season Heterosexual Relationships in Free-ranging Rhesus Macaques
}

JOSEPH H. MANSON

The University of Michigan

\begin{abstract}
Birth season adult heterosexual nonkin relationships of 50 free-ranging female rhesus macaques (Macaca mulatta) in two social groups at Cayo Santiago, Puerto Rico were examined using focal follow $(289 \mathrm{hr})$ and ad lib data. Eighty-eight percent of subjects had at least one relationship characterized by particularly high frequencies of spatial proximity, grooming, or both. These were designated "friendships." Males intervened in aggressive interactions more frequently on behalf of Friends than non-Friends. Female aggressive support of males was extremely rare. Higher-ranking males experienced more friendships than lower-ranking males. High-ranking females had higherranking Friends than low-ranking females. Older females had higher-ranking Friends than younger females. Females groomed high-ranking Friends more than they were groomed by them, whereas they groomed low-ranking Friends less than they were groomed by them. In one social group, high-ranking females were more likely than low-ranking females to groom their Friends more than they were groomed by them. Males were more responsible than females for spatial proximity maintenance in 9 of 14 Friend dyads for which sufficient data were available. Neither male nor female dominance rank affected responsibility for proximity maintenance in Friend dyads.

Eight of 24 females had friendships with males with whom they had completed copulations during their conception peri-ovulatory period of the preceding mating season. Two of 19 females completed peri-ovulatory copulations with Friends during the following mating season. Friendship was not correlated with either of two demonstrated female mate choice indicators: (1) proximity maintenance during estrus; or (2) cooperation with male "hip-grasp"' courtship attempts. Males directed "'muzzleup" courtship signals at lower rates toward Friends than toward non-Friends.

These and other investigators' results indicate that (1) protection from aggression is the primary benefit to female rhesus macaques of birth season heterosexual relationships; (2) the most effective protectors are in greatest demand as Friends; and (3) friendship has no effect or an inhibitory effect on mate choice in this species. Benefits to males of friendships were not apparent from this study but may include coalitional support against lower-ranking males.
\end{abstract}

Key Words: Macaca mulatta; Heterosexual relationships; Mate choice; Cayo Santiago.

\section{INTRODUCTION}

In a number of multimale group living primate species, unrelated adult heterosexual pairs maintain affiliative relationships for periods of months or years while the female is not sexually active (RANSOM \& RANSOM, 1971; TAKAHATA, 1982a; ChAPAIS, 1983a; SMUTS, 1985; HILL, 1990; HUFFMAN, 1991a, b). Reciprocal altruism theory (TRIVERS, 1971; AXElRoD \& Hamilton, 1981) and game theory (MAynard SMith, 1982; KaHAN \& RAPOPORT, 1984; NOË, 1990) lead to the expectations that (1) individual animals establish and maintain social relationships to obtain reproductively relevant benefits from partners while minimizing costs and (2) each individual has a characteristic value as a social partner that affects its access to partners. Thus, participants in adult heterosexual dyadic 
affiliative relationships are expected to exchange helping acts such that each animal experiences a net gain greater than the gain that would accrue from alternative available relationships. Which alternatives are "available" depends on the participant's value as a partner, which can be difficult to assess but is presumably influenced by variables such as age and dominance rank. Available evidence conforms generally to the reciprocity hypothesis for sustained affiliative heterosexual relationships among nonkin in savanna baboons, macaques, and chimpanzees (SMUTS, 1985). Following SMUTS (1985), I will call these relationships "friendships." In this paper, building on other researchers' results (Chapais, 1983a; HiLl, 1990), I use new data to examine heterosexual friendship in freeranging rhesus macaques (Macaca mulatta), with particular attention to the question of whether friends are chosen as mates.

The benefits exchanged by friends vary across species. Male savanna baboons protect their Friends and their Friends' infants from aggression by conspecifics, while females (1) allow their Friends to use their infants as "buffers" in intermale aggressive confrontations and (2) spend more time in sexual consort with Friends than would be expected given the male's overall level of consorting activity (SMUTS, 1985). Thus, from the male viewpoint, friendships may primarily represent mating effort rather than parental effort. Almost all females, and all but the most recent immigrant males, have at least one Friend.

Among Japanese macaques, females as well as males aid their friends in agonistic interactions (TAKAHATA, 1982a; HuFFMAN, 1991b), and female support is sometimes crucial to the maintenance of high male dominance rank. Males form affiliative relationships with their friends' infants, and do not use these infants as buffers. Compared to savanna baboons, a larger proportion of adult females have no friends. Among males, dominance rank and tenure correlate positively with number of friends. Pairs of friends avoid copulating after the first one to two years of friendship, apparently because of female sexual aversion.

Studies of rhesus macaque heterosexual relationships (CHAPAIS, 1983a; Hill, 1990) suggest a pattern of friendship similar to that of Japanese macaques. However, no studies of rhesus friendships have involved multi-year collection of focal individual data. CHAPAIS (1983a) observed subjects for a single birth season followed by a single mating season, whereas Hill's (1990) study encompassed two birth seasons and an intervening mating season. Furthermore, no quantitative data have been published on how or whether friendship affects macaque female mate choice, as distinct from mere likelihood or frequency of copulation. This is an important distinction because other forces besides female mate choice (e.g. male sexual coercion: SMUTS \& SMUTS, 1992) affect mating patterns. Mate choice may be defined as "any pattern of behavior, shown by members of one sex, that leads to their being more likely to mate with certain members of the opposite sex than others" (HALLIDAY, 1983: 4). Female choice may increase males' sexual access to their friends above the level that these males would otherwise experience.

Here I present evidence from free-ranging rhesus macaques on (1) fertile period matings and empirically validated female choice behaviors (MANSON, 1992) in a set of heterosexual dyads during two consecutive mating seasons and (2) friendships during the intervening birth season. This study design allows me to assess concordances between (1) fertile period matings and subsequent birth season friendships; (2) birth season friendships and subsequent fertile period matings; and (3) birth season friendships and subsequent female mate choice behavior and male courtship behavior.

Additionally, I build on CHAPAIS' (1983a) and Hill's (1990) descriptive studies of rhesus 
birth season friendships by presenting evidence pertaining to (1) relationships of female rank and age, and of male rank, age, and breeding tenure to number and ranks of friends; (2) mutual agonistic support in friend dyads; and (3) variation among dyads in responsibility for grooming and proximity maintenance. These data have implications for understanding the effects of an animal's value as a social partner on its access to opposite-sexed friends.

\section{METHODS AND SUBJECTS}

\section{Study Species And Site}

The subjects of my study were adult ( $\geq 4.5$ yr old in June 1988) female rhesus macaques of two social groups (Groups T and Q) on Cayo Santiago, a 15-ha island $1 \mathrm{~km}$ off the southeast coast of Puerto Rico. Table 1 shows the age-sex compositions of the study groups. One of the 51 adult females of the study groups died in November 1988 (i.e. early in the birth season); data collected on this female are not included in analyses presented in this paper.

The monkeys of Cayo Santiago are provisioned and are trapped anually for identification marking. A biweekly census of the entire population updates a database of births, deaths, intergroup transfers, and group fissions covering the entire period since 1956. Periodic removal of entire social groups keeps the population between approximately $600-1,400$. Otherwise, the monkeys are free-ranging and are not handled or interfered with (for more information about Cayo Santiago management and history, see AltmanN, 1962; SAdE et al., 1985; RAWLINS \& KESSLER, 1986). Social groups are considerably larger, and adult sex ratios closer to $1: 1$, than in wild rhesus macaques on the Indian subcontinent (see, e.g. MALIK et al., 1984; MELNICK et al., 1984). Group T contained 104-126 animals, and Group Q contained 126-142 animals, during the study. Adult sex ratios (males:females) ranged from $1.48-1.37$ in Group T, and from .67- .83 in Group Q (see MANSON, 1992).

Table 1. Composition of study groups by age-sex class.

\begin{tabular}{lccccc}
\hline & \multicolumn{2}{l}{ Group Q } & & \multicolumn{2}{c}{ Group T } \\
\cline { 2 - 3 } \cline { 5 - 6 } Age-sex class & June 1988 & June 1989 & & June 1988 & June 1989 \\
\hline Adult males $^{1)}$ & $25(4)$ & $24(6)$ & & $31(3)$ & $37(7)$ \\
Subadult males $^{2)}$ & $6(5)$ & $3(3)$ & & $6(3)$ & $5(5)$ \\
Adult females $^{3)}$ & 30 & 36 & & 21 & 27 \\
Adolescent females $^{4)}$ & 7 & 6 & 6 & 4 \\
Juveniles and infants $^{5)}$ & 58 & 74 & & 40 & 53 \\
Total & 126 & 142 & 104 & 126 \\
\hline
\end{tabular}

Numbers in parentheses: Natal males. 1) $\geq 5.5$ yr old; 2) 4.5 yr old; 3) $\geq 4.5$ yr old; 4) 3.5 yr old; 5) males $<4.5$ yr old plus females $<3.5$ yr old.

\section{Measures And Definitions}

Rhesus macaques are series mounters. Mating pairs engage in up to 100 non-ejaculatory mounts with intromission before the final ejaculatory mount, discernible by a characteristic pause and rigid posture by the male. I defined mount series culminating in ejaculation, 
as well as (rare) single mounts ending in ejaculation, as "copulations." Behavioral endocrinological studies (CATCHPOLE \& VAN WAGENEN, 1978; GORDON, 1981) show that ovulation usually occurs during the four days preceding an estrous female's abrupt decline in sexual attractiveness, or "attractiveness breakdown" (as defined by CHAPAIS, 1983b; MANSON, 1992); I refer to copulations occurring on these days as "peri-ovulatory copulations." I regarded a female as being in estrus from the day she was first seen in a mount series, or with a mating plug (coagulated ejaculate on her perineum), until the day after her attractiveness breakdown.

An "approach" was scored when one animal decreased the distance between itself and another animal by at least one half $\mathrm{m}$ and stopped or sat, with the final distance between them being less than $4 \mathrm{~m}$ (during follows of estrous females) or $1 \mathrm{~m}$ (during birth season follows). A "leave" was scored when one animal increased the distance between itself and another animal by at least one half $\mathrm{m}$, with the initial distance between them being less than $4 \mathrm{~m}$ (estrous) or $1 \mathrm{~m}$ (birth season). Approaches and leaves taking place at the artificial drinking stations were excluded from analyses, as were "leaves" during chases. I used approaches and leaves to calculate HINDE's index (HINDE \& ATKINSON, 1970) for heterosexual dyads. This index measures responsibility for maintaining spatial proximity. In Group Q, female responsibility for proximity maintenance during estrus was positively correlated with peri-ovulatory copulation rate, thus establishing this behavior as a form of female mate choice (MANson, 1992).

A dominance interaction was scored whenever one animal supplanted another (approached and took its spot immediately after the approached animal vacated it) or when the approach of one animal caused another to "grimace" (retract the lips and cheeks, exposing the teeth), "cower" (lean downward and away from the approaching animal), or flee. I ascertained adult male dominance relationships by arranging males in matrices showing winners of dominance interactions along one axis and losers along the other.

A "sexual refusal" was scored when a female responded to a male's "hip-grasp" (grasping the female's hips with both hands from behind) by refusing to "present" (stand up to be mounted) to begin a mount series. Females refused by either remaining seated or moving away. Heterosexual dyads in which estrous females refused a higher proportion of the male's hip-grasps completed peri-ovulatory copulations at lower rates than dyads in which females refused a lower proportion of hip-grasps, thus establishing sexual refusals as a form of female mate choice (MANSON, 1992).

A "muzzle-up" was scored when a male moved his face close to a female's face, smacked his lips, and then moved away. This is a courtship signal directed toward estrous females (ALtManN, 1962).

Heterosexual agonistic interventions were defined as incidents in which a male intervened on a female's behalf during an aggressive interaction (involving vocalizations, chasing, or physical contact) between her and a male or a higher-ranking female (interventions against lower-ranking females are probably superfluous and involve little cost to the intervening male).

From the Cayo Santiago longterm database, I obtained (1) each animal's birth year; (2) each female and natal male's matriline (a matriline is defined as a group of monkeys descended from the same common ancestress among the females alive in 1956); and (3) each male's breeding tenure in months (since entering the group for immigrants, and since June of the male's fifth year for natal males). There were two natal matrilines in Group T, and three in Group Q. Throughout this paper, "nonkin"' and "unrelated"' refer only to 
lack of matrilineal relationship. Genealogical relationships through males are unknown.

\section{Data COllection AND AnAlysis}

One to four observers collected data on 211 days during two mating seasons (1988 and 1989) and on 124 days during the intervening birth season. Ad lib (ALTMANN, 1974) observations provided information about dominance relationships and cycling females' reproductive states. During the mating seasons, we conducted 2 -hr focal individual follows (AltMANN, 1974), divided into 30-min sampling blocks with no more than 5 min between them, on females chosen randomly from those judged to be in estrus on the preceding day. Data from uncompleted 2-hr follows were used in the analyses described here, except for uncompleted 30-min sampling blocks, which were discarded. During follows, we used checksheets to record all approaches and leaves, and all occurrences of 54 social behaviors, displayed by or directed toward the focal female. We also recorded the female's current activity, nearest adult male neighbor, and other adult neighbors within $10 \mathrm{~m}$ every $3 \mathrm{~min}$ on an instantaneous basis. Follows were temporarily discontinued when focal subjects entered the fenced-in feeding corrals.

To ensure inter-observer reliability, all observers were required to meet a standard of $90 \%$ concordant records with mine, over four consecutive 30-min focal follows. Data collected during these test sessions were not analyzed.

During the birth season, each adult in the two study groups with one exception was a focal subject in $22-2415-\mathrm{min}$ focal follows. (One female was a subject in 12 follows because she developed an intense fear of humans in the middle of the birth season). Subjects were selected for focal follows on the following schedule: one sampling block was completed when each of the 50 females had been followed once. A sampling block had to be completed before a female who had been followed during that block could be followed again. Thus, no female could be followed more than twice between the successive follows of any other female. Also, no female could be followed on consecutive days. Furthermore, to control for possible time-of-day effects, the 8-hr observation day (07:00 - 15:00) was divided into four 2-hr segments. Once a female was followed starting within a particular 2-hr segment, she could not be followed during that segment again until she had been followed in each of the other three segments. Finally, a follow could not be started on a female who was within $10 \mathrm{~m}$ of the previously followed female.

During these follows, the same data collection protocol was used as during mating season follows of estrous females, except (1) point samples were recorded every 2 min rather than every $3 \mathrm{~min}$; (2) individuals between 4 and $10 \mathrm{~m}$ of the focal subject were not noted during point sample recording; and (3) approaches and leaves were recorded only when they occurred within $1 \mathrm{~m}$ (rather than $4 \mathrm{~m}$ ) of the focal subject. These differences from the estrous sampling protocol reflect observed differences between estrous female behavior and birth season female behavior. In the latter context, females tend to (1) behave less actively (allowing more frequent point samples without loss of reliability) and (2) stay closer to the center of the group (where animals are concentrated so heavily that proximity beyond $4 \mathrm{~m}$, and approaches and leaves outside $1 \mathrm{~m}$, are probably mostly meaningless to the monkeys). All data used to define friendship were collected during the birth season.

Significance of results was determined using nonparametric statistical tests. Kendall partial correlation significance levels are from MAGHSOODLOO (1975) and MAGHSOODLOO and Laszlo Pallos (1981). All tests are two-tailed. 


\section{DEFINITION OF FRIENDSHIP}

I defined friendship using methods described by SMUTS (1985). Two criteria were used: proximity during focal observation, and grooming during ad lib observation. Grooming during focal follows was too rare to permit reliable inferences based on focal data alone. Grooming and spatial proximity have widely demonstrated validity as measures of nonhuman primate affiliative social relationships among both kin (reviewed by Gouzoules \& GOUZOULES, 1987) and nonkin (reviewed by WALTERS \& SEYFARTH, 1987).

Using proximity data collected at the point samples, I assigned each adult heterosexual nonkin dyad a composite proximity score $(C$ score) using the following formula:

$$
C=\frac{2\left(M_{1 m}\right)+.4\left(M_{1}-4 m\right)}{H},
$$

where: $M_{1 m}$ : min spent within $1 \mathrm{~m} ; M_{1-4 m}$ : min spent between 1 and $4 \mathrm{~m} ; H$ : hrs of focal observation of that female.

The constants 2 and .4 represent weighting factors to compensate for the greater distance between individuals possible in the $1-4 \mathrm{~m}$ category. They were calculated as the reciprocal of the midpoint between the inner and outer limits of the distance category.

During ad lib observation, we observed 1,088 adult heterosexual grooming bouts among nonkin. Separate bouts were recorded for the same dyad on the same day only when grooming was observed on separate instances (1) at least $30 \mathrm{~min}$ apart and (2) in different places. I sought to determine whether each dyad that groomed at least once groomed more than expected by chance. The probability $\left(P_{m}\right)$ that a female would groom with a favorite grooming partner as often as observed was calculated as follows. Under the null hypothesis, I assumed that for each grooming episode the probability that a female would groom with male " $m$ " $\left(G_{m}\right)$ was equal to the proportion of all grooming episodes between males and females that involved male $m$. Using the formula for the binomial expansion,

$$
P_{m}=\sum_{i=x}^{n}\left(\begin{array}{l}
n \\
i
\end{array}\right)\left(G_{m}\right)^{i}\left(1-G_{m}\right)^{n-i}
$$

where $n$ : the female's total number of grooming episodes with any male; $x$ : the observed number of grooming episodes with male $m$, and $G_{m}$ is defined as above (SMUTS, 1985). Dyads with values of $P_{m}$ less than .05 were considered to have groomed together more frequently than expected by chance.

\section{RESULTS}

\section{DOMINANCE RELATIONSHIPS}

Like previous investigators of rhesus macaques (e.g. KAUFMANN, 1967; SADE, 1967; VESSEY \& MeIKLE, 1987; Berard, 1990), I found that (1) both sexes form linear dominance hierarchies; (2) adult female dominance rank is genealogically determined, such that (a) each female holds a rank below her mother and above her next oldest sister and (b) entire matrilines can be ranked relative to one another; and (3) immigrant male dominance rank is strongly positively correlated with group tenure (MANSON, 1992). For analytical purposes, dominance rank is expressed as "proportion of males dominated" throughout this paper. 


\section{Nonkin Heterosexual Proximity and Grooming}

If females associated with males at random, distributions of males' $C$ scores for each female would be more or less continuous. However, when the distribution of $C$ scores across males was calculated for each female, 32/50 (64\%) had one to four males whose $C$ score was at least one unit above all the others on the scale of measurement $(\bar{X}=1.08$ males per female with these $C$ scores, range $=0-3$ ). Dyads with these $C$ scores will be called Preferred Proximity Dyads. Figure 1 illustrates the distribution of males' $C$ scores for three females that were selected to illustrate the range of $C$ score patterns among females.

Excluding dyads in which two or fewer grooming bouts were observed (to increase reliability), 39/50 (78\%) of females had at least one male with whom she groomed more than expected by chance $(\bar{X}=1.14$ males per female, range $=0-3)$. Dyads that groomed more frequently than expected by chance will be called Preferred Grooming Dyads.

I classified all dyads that were either Preferred Proximity or Preferred Grooming Dyads as Friends. Using this definition, there were 52 Friend dyads in Group Q (out of a total of 565 possible dyads) and 32 Friend dyads in Group $T$ (out of a total of 754 possible dyads). Females averaged 1.66 Friends ( $\mathrm{sd}=1.00$, range $=0-4)$. Of the 50 subjects, $43(86 \%)$ had at least one Friend. In the remainder of this paper, I will capitalize the word "friend" where it has been defined using explicit behavioral criteria [i.e. in this study and in SMUTS' (1985) study].

\section{Distribution of Friendships by Rank, Age, Tenure, and Kinship}

Table 2 shows friendships broken down by male's rank class. It also shows the number of dyads of that type that were "available" for friendship formation in the social group. Friendships were concentrated among high-ranking males. Table 3 shows correlations of male (1) dominance rank and (2) breeding tenure with number of Friends. Partial eorrelation analysis shows that dominance rank was more strongly correlated than breeding tenure with number of Friends.

Table 2. Distribution of friendships by male dominance rank.

\begin{tabular}{|c|c|c|c|c|c|c|}
\hline \multirow[b]{2}{*}{ Rank class } & \multicolumn{3}{|l|}{ Group Q } & \multicolumn{3}{|l|}{ Group T } \\
\hline & Friendships & Possible friendships ${ }^{2}$ & $\%$ & Friendships & Possible friendships ${ }^{2)}$ & $\%$ \\
\hline Top $25 \%{ }^{1)}$ & $\overline{33}$ & 111 & 29.7 & 22 & 173 & 12.7 \\
\hline Second $25 \%{ }^{1)}$ & 13 & 149 & 8.7 & 8 & 210 & 3.8 \\
\hline Bottom $50 \%{ }^{1)}$ & 6 & 305 & 2.9 & 2 & 371 & 0.5 \\
\hline
\end{tabular}

1) Of male dominance hierarchy; 2) number of adult heterosexual non-kin dyads that included males of that rank class.

Table 3. Correlations between male dominance rank, breeding tenure, and number of Friends.

\begin{tabular}{lllllc}
\hline Social group & Independent variable & Variable held constant ${ }^{\prime \prime}$ & $\left.N^{2}\right)$ & $\tau^{3)}$ & \multicolumn{2}{c}{$p$} \\
\hline T & Rank & - & 44 & .414 & .00004 \\
T & Tenure & - & 44 & .377 & .0002 \\
T & Rank & Tenure & 44 & .306 & $<.01$ \\
T & Tenure & Rank & 44 & .248 & $<.02$ \\
Q & Rank & - & 24 & .65 & .0001 \\
Q & Tenure & - & 24 & .56 & .0001 \\
Q & Rank & Tenure & 24 & .47 & $<.002$ \\
Q & Tenure & Rank & 24 & .258 & $>.05$ \\
\hline
\end{tabular}

1) In partial correlation analyses; 2) number of males; 3) Kendall's $\tau$. 


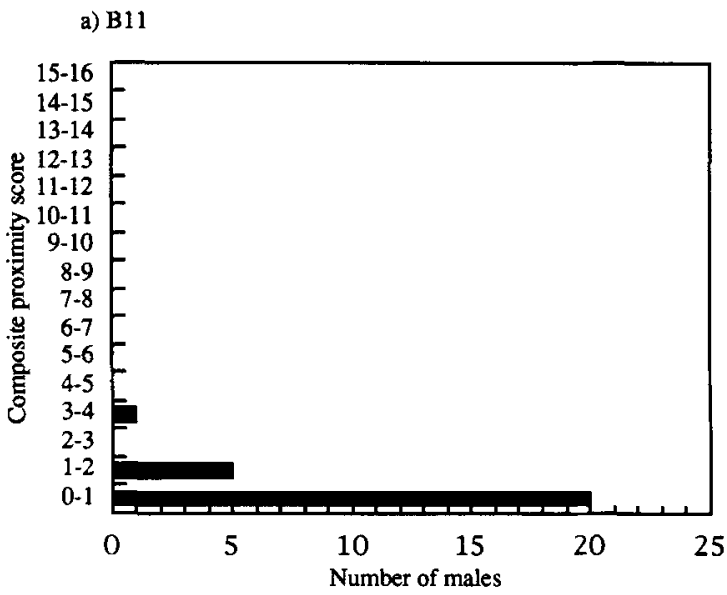

a

b) 526

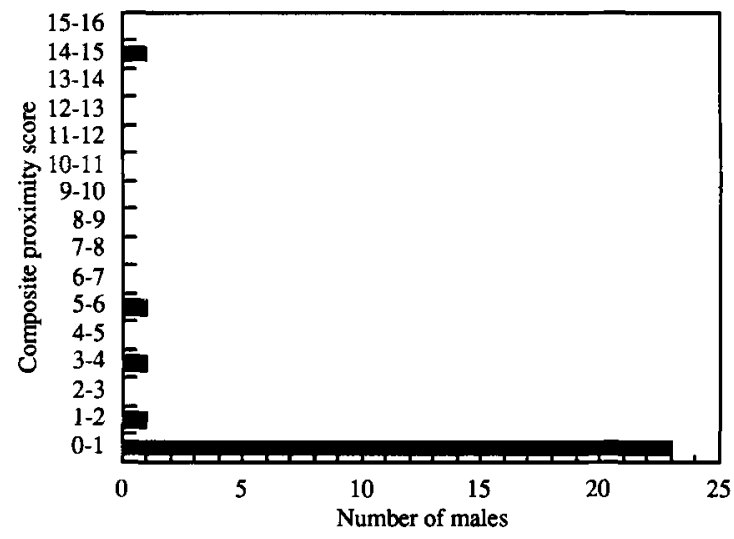

b

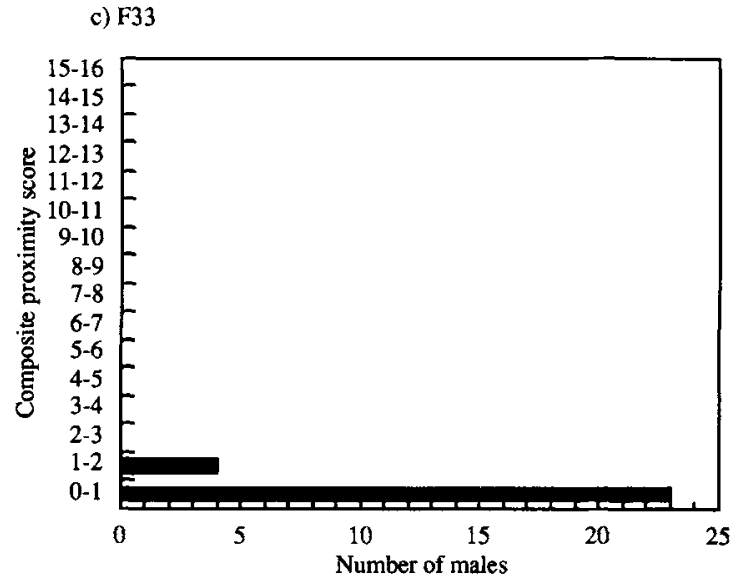

c

Fig. 1. Distribution of composite proximity scores $(C$ scores) for three selected Group $Q$ adult females $(B 11,526$, and $F 33)$ with all Group Q adult males. 
Female dominance rank and age were related to the dominance ranks of male Friends. In Group $T$, the mean rank (proportion of males dominated) of Friends of high-ranking females (i.e. females of the higher-ranking matriline) was marginally higher than that of low-ranking females $\left(N_{l}=4\right.$ high-rankers, $N_{2}=14$ low-rankers, $\bar{X}_{1}=.932, \bar{X}_{2}=.771$, $U=11.5, p=.079$ ). In Group Q, the Friends of members of the highest ranking matriline were higher-ranking than those of the lowest ranking matriline $\left(N_{1}=8, N_{2}=13, \overline{\mathrm{X}}_{1}=.924\right.$, $\overline{\mathrm{X}}_{2}=.762, U=22, p=.029$ ). In both groups, older females' Friends had higher mean dominance ranks than younger females (Group T: $N=18$ females, $\tau=.62, p=.0003$; Group $\mathrm{Q}: N=25, \tau=.447, p=.0017)$. Female dominance rank and female age were not correlated (Group T: $N=18, \tau=.23, p=.19$; Group Q: $N=25, \tau=-.07, p=.63$ ).

Male Friends tended to be shared among related females. Of the 43 females with at least one Friend, $33(76.7 \%)$ shared at least one Friend with a sister, mother, daughter, grandmother, or granddaughter. Of the 34 females in the sample with living mothers, $19(55.9 \%)$ shared at least one Friend with their own mothers.

\section{Friends as Agonistic Supporters}

During focal and ad lib observation combined, we observed 92 male agonistic interventions on behalf of females. Males never supported unrelated females in agonistic interactions against higher-ranking males. To test whether the observed number of male interventions on behalf of Friends was greater than that expected by chance, I scored whether at least one such intervention occurred in each adult heterosexual dyad in which (1) the male intervened at least once on behalf of some female and (2) both the male and the female had at least one friendship. Agonistic interventions were more likely to be observed in Friend than non-Friend dyads in both groups (Table 4: $\chi^{2}=36.59, p<.0001$ ).

Female aggressive support for unrelated males was observed only three times (see CHAPAIS, 1983a for contrasting results). None of these cases involved Friend dyads.

Table 4. Male aggressive interventions on behalf of Friends and non-Friends.

\begin{tabular}{llc}
\hline & One or more male interventions & No male interventions observed \\
\hline Friend dyads & 28 & 41 \\
Non-Friend dyads & 28 & 254 \\
\hline
\end{tabular}

Cells contain numbers of dyads.

\section{Responsibility for Birth Season Grooming and Proximity Maintenance}

Of 14 Friend dyads that had at least 10 summed approaches and leaves during birth season focal follows, Hinde's Indices were negative (i.e. the male was more responsible for proximity maintenance) in nine cases $(64.3 \%$ ). I classified grooming bouts observed during ad lib observation according to whether the male or the female was grooming when the pair was first observed grooming. In 30 of 62 Preferred Grooming Dyads, the male was the first observed groomer in more than $50 \%$ of the observed grooming bouts; in 28 dyads, the female was the first observed groomer in more than $50 \%$ of the observed grooming bouts; and in the remaining 4 dyads, both the male and the female were the first observed groomer in exactly $50 \%$ of the observed grooming bouts. 
Across Friend dyads in Group T, female dominance rank (i.e. matriline membership) was not associated with either Hinde's Index $\left(N_{l}=5\right.$ dyads involving high-ranking females, $N_{2}=4$ dyads involving low-ranking females, $\left.U=10, p>.50\right)$ or proportion of grooming bouts in which the female was the first observed groomer $\left(N_{1}=6, N_{2}=20, U=50, p>.50\right)$. Male dominance rank was not correlated with Hinde's Index ( $N=9$ dyads, $\tau=.062, p>.50$ ), but male dominance rank was positively correlated with the proportion of ad lib grooming bouts in which the female was the first observed groomer $(N=26, \tau=.33, p=.018)$. In Group Q, there were too few Friend dyads with ten or more summed approaches and leaves $(N=5)$ for statistical analysis. Friend dyads involving high-ranking (as opposed to low-ranking) females has marginally higher proportions of grooming bouts in which the female was the first observed groomer $\left(N_{I}=9, N_{2}=19, U=46.5, p=.055\right)$. As in Group T, male dominance rank was positively correlated with the proportion of ad lib grooming bouts in which the female was the first observed groomer $(N=35, \tau=.51, p=.0001)$. When Friend dyads were divided by social group and matriline rank, the correlation between male dominance rank and proportion of ad lib grooming bouts in which the female was the first observed groomer was statistically significant $(p<.05)$ only for low-ranking females of Group T, and only for high-ranking females of Group Q.

\section{MALE-INFANT INTERACTIONS}

On 14 occasions, we observed adult or subadult males interacting affiliatively (grooming, holding, or playing) with infants whose mothers were identified. In 11 of these cases, the male and the infant's mother were Friends. In three cases they were matrilineally related, including one case in which the male was the infant's subadult brother.

\section{FRIENDSHIP AND MATING}

I examined whether possible fathers of infants conceived in 1988 became Friends of these infants' mothers in the 1988-1989 birth season. Possible fathers were defined as those males observed to complete at least one copulation with the mother during her conception peri-ovulatory period. The conception cycle was determined by backdating 168 days from parturition, using STOLTE's (1978) estimate of rhesus macaque gestation length.

In the two study groups combined, there were 24 females (1) whose 1989 infants (i.e. those conceived in the 1988 mating season) could be assigned at least one possible father and (2) that had at least one Friend during the 1988-1989 birth season. Two females' infants had three possible fathers; the remaining 22 females' infants had one possible father. Thus, there were 28 dyads consisting of a female and a possible father of her infant. Eight of the 24 females $(33.3 \%)$ had a friendship with at least one possible father. In eight heterosexual dyads, a high-ranking (i.e. in the top $25 \%$ of the male dominance hierarchy) immigrant male was a possible father of an infant, and five of these dyads were Friends during the following birth season. In 14 heterosexual dyads, a high-ranking natal male (of a different matriline from the mother's matriline) was a possible father. Only one of these dyads had a friendship during the following birth season. In six dyads, a non-high-ranking immigrant male was a possible father. Two of these dyads had a friendship during the following birth season.

In summary, females were apparently frequently impregnated by natal males of matrilineages other than their own (see MAnson \& PERrY, 1993; MANSON, 1993), whereas their birth season Friends tended to be high-ranking immigrant males with whom they had not been observed to mate during their fertile periods. Whether peri-ovulatory copulatory 
partners tended to become Friends in the following birth season is difficult to assess statistically because the set of males that copulated with peri-ovulatory females in 1988 did not overlap strongly with the set of males that had Friends during the $1988-1989$ birth season. Sixteen males were observed to complete peri-ovulatory copulations. Eighteen males had a friendship with at least one of the females that had completed at least one observed peri-ovulatory copulation. Only 7 of 27 males $(26 \%)$ were in both categories. This lack of overlap between sets of Friends and likely fathers itself is evidence against any strong connection between possible paternity and subsequent friendship, but it makes quantitative testing difficult because of problems in constructing a random distribution with which to compare the observed distribution.

Of 19 females that (1) had at least one Friend and (2) were observed to complete at least one peri-ovulatory copulation during the following (1989) mating season, 2 completed a peri-ovulatory copulation with a Friend. The set of males that had friendships did not overlap strongly with the set of males that completed at least one 1989 peri-ovulatory copulation. Twenty-two males were observed to complete peri-ovulatory copulations. Eighteen males had a friendship with at least one of the females that completed at least one observed peri-ovulatory copulation. Only 9 of 31 males $(29 \%)$ were in both categories. Again, this itself is evidence against any substantial connection between friendship and subsequent fertile copulation, but it precludes determining whether males' chances of completing peri-ovulatory copulations with Friends were greater than would be expected given each male's overall level of peri-ovulatory mating activity.

The pattern of friendships was more concordant with peri-ovulatory copulation partnerships in the preceding (1988) mating season than in the following (1989) mating season [ 8 of 24 females $(33.3 \%)$ vs 2 of 19 females $(10.5 \%)$ having at least one male in both the Friend and peri-ovulatory mate categories]. This difference cannot be tested statistically because the data points are not independent: some dyads contribute to the totals in two cells when the data are arranged in a two-by-two matrix.

\section{FRIENDSHIP AND MATE CHOICE}

I examined whether friendship was a significant predictor of the occurrence of the female behavior patterns (proximity maintenance and cooperation with hip-grasp attempts) shown (MANSON, 1992) to represent mate choice. First, each Friend dyad that had ten or more summed approaches and leaves during the female's 1989 estrous period was classified according to whether its Hinde's Index was above or below the male's median Hinde's Index with estrous females. This procedure controls for intermale differences in overall sexual attractiveness. Nine Friend dyads were above the male's median, eight below, and two at the median. To test whether birth season friendship increases male sexual attractiveness to particular females between consecutive mating seasons, dyads (1) for which estrous period Hinde's Indices were available for both 1988 and 1989, and (2) in which the male of the dyad had at least one friendship were separated into Friend and

Table 5. Friendship and change in Hinde's index, 1988 to 1989.

\begin{tabular}{lcl}
\hline & $\begin{array}{l}\text { Positive change } \\
\text { (more female proximity maintenance) }\end{array}$ & $\begin{array}{l}\text { Negative change } \\
\text { (less female proximity maintenance) }\end{array}$ \\
\hline Friend dyads & 7 & 5 \\
Non-Friend dyads & 13 & 13 \\
\hline
\end{tabular}

Cells contain numbers of dyads. 
Table 6. Friendship and sexual refusals.

\begin{tabular}{lllc}
\hline & & Friend dyads & Non-Friend dyads \\
\hline Proportion of hip-grasps refused & All & 3 & 9 \\
& Some & 4 & 19 \\
& None & 4 & 39 \\
\hline
\end{tabular}

Cells contain numbers of dyads.

non-Friend dyads. Friends were no more likely than non-Friends to have positive changes in Hinde's Index between the two mating seasons (Table 5: $\chi^{2}=.017, p>.50$ ).

Females did not refuse a smaller proportion of hip-grasp attempts in Friend than in non-Friend dyads (Table 6). In fact, there was a nonsignificant trend in the opposite direction, regardless of whether dyads in which some hip-grasps were refused were classified with the all dyads (Yates' corrected $\chi^{2}=1.047, p=.33$ ) or with the none dyads $\left(\chi^{2}=.530\right.$, $p=.466$ ) (see MANSON, 1992).

\section{FRIENDSHIP AND MALE COURTSHIP}

Males that had at least one Friend directed "muzzle-ups" at lower rates toward Friends that toward non-Friends during the 1989 mating season (mean of individual males' mean rates toward Friends $=.083$ muzzle-ups per hr; toward non-Friends $=.22$ muzzle-ups per $\mathrm{hr}$; Wilcoxon test, $N=17$ males, $T=12.5, p=.0024$ ).

\section{DISCUSSION}

Table 7 shows that my results conform generally to those reported for the same population by CHAPAIS (1983a, 1986) and HiLl (1990), even though data collection protocols and analytical procedures differed among the studies. I regard HILL's "persistent proximity partners"' as well as CHAPAIS' (1983a, 1986) grooming relationship types A-E as roughly equivalent to Friend dyads in my study. In all three studies, most females had at least one birth season friend.

Unique conclusions of my study include: (1) female age was positively correlated with average dominance rank of male Friends; (2) friendships were slightly more concordant with past copulation partnerships than with future partnerships, although this difference cannot be statistically tested; (3) occurrence of two demonstrated estrous female mate choice signals - proximity maintenance and cooperation with male hip-grasp attempts were not functions of prior friendship, even (in the case of proximity maintenance) controlling for the male's overall sexual attractiveness; (4) friendship during the intervening birth season had no effect (positive or negative) on year-to-year changes in responsibility for dyadic proximity maintenance by estrous females; and (5) males directed fewer "muzzleup" courtship signals toward Friends than toward non-Friends. Thus, mate choice is not a benefit conferred by female rhesus macaques on their male Friends. Apparent male sexual aversion toward Friends is difficult to interpret. Males may learn that Friends are not likely to copulate with them. Similar logic seems to apply to courtship between matrilineally related rhesus macaques (MANSON \& PERRY, 1993).

CHAPAIS (1983a), Hill (1990), and I all found that friendships were concentrated among high-ranking males. Because (1) males tend to intervene in aggressive interactions on behalf of Friends in preference to non-Friends; (2) males never intervene on behalf of nonkin 
Table 7. Summary of findings of studies of rhesus macaque friendship.

\begin{tabular}{|c|c|c|c|}
\hline $\begin{array}{l}\text { Relationship between } \\
\text { friendship and }\end{array}$ & Chapais $(1983 a, 1986)$ & HiLL (1990) & This study \\
\hline Direction of grooming & $\begin{array}{l}\text { Depends on animals' } \\
\text { dominance ranks }\end{array}$ & $\begin{array}{l}\text { Depends on animals' } \\
\text { dominance ranks }\end{array}$ & $\begin{array}{l}\text { Depends on animals' } \\
\text { dominance ranks }\end{array}$ \\
\hline $\begin{array}{l}\text { Responsibility for } \\
\text { proximity maintenance }\end{array}$ & $\begin{array}{l}\text { Mostly female, except in } \\
\text { dyads including the } \\
\text { alpha female }\end{array}$ & Mostly female & No sex bias \\
\hline Male dominance rank & $\begin{array}{l}\text { Positively correlated } \\
\text { with number of Friends; } \\
\text { high-rankers were } \\
\text { groomed more than they } \\
\text { groomed (except in } \\
\text { dyads including the } \\
\text { alpha female); low- } \\
\text { rankers opposite }\end{array}$ & $\begin{array}{l}\text { Positively correlated } \\
\text { with number of Friends; } \\
\text { high-rankers were } \\
\text { groomed more than they } \\
\text { groomed; low-rankers } \\
\text { opposite }\end{array}$ & $\begin{array}{l}\text { Positively correlated } \\
\text { with number of Friends; } \\
\text { high-rankers were } \\
\text { groomed more than they } \\
\text { groomed; low-rankers } \\
\text { opposite }\end{array}$ \\
\hline Female dominance rank & $\begin{array}{l}\text { Alpha female highly } \\
\text { attractive social partner, } \\
\text { as shown by directions } \\
\text { of grooming and } \\
\text { proximity maintenance }\end{array}$ & $\begin{array}{l}\text { Higher-ranking females } \\
\text { had higher-ranking } \\
\text { Friends }\end{array}$ & $\begin{array}{l}\text { Higher-ranking females } \\
\text { had higher-ranking } \\
\text { Friends }\end{array}$ \\
\hline Agonistic support & $\begin{array}{l}\text { Mutual between females } \\
\text { and high-ranking males; } \\
\text { support directed against } \\
\text { subordinate males }\end{array}$ & $\begin{array}{l}\text { Very rare; possibly not } \\
\text { concordant with } \\
\text { friendship }\end{array}$ & $\begin{array}{l}\text { Males commonly } \\
\text { supported females, } \\
\text { preferring Friends; } \\
\text { female support of males } \\
\text { very rare, not concordant } \\
\text { with friendship }\end{array}$ \\
\hline Mating patterns & $\begin{array}{l}\text { No concordance between } \\
\text { friendship and } \\
\text { subsequent fertile period } \\
\text { copulation }\end{array}$ & $\begin{array}{l}\text { No concordance between } \\
\text { friendship and } \\
\text { subsequent consortship } \\
\text { occurrence or quality }\end{array}$ & $\begin{array}{l}\text { No concordance between } \\
\text { friendship and } \\
\text { subsequent fertile period } \\
\text { copulation or female } \\
\text { mate choice; males court } \\
\text { Friends less than non- } \\
\text { Friends; friendship may } \\
\text { be more concordant } \\
\text { with past than with } \\
\text { future fertile period } \\
\text { copulation }\end{array}$ \\
\hline $\begin{array}{l}\text { Group size(s) } \\
\text { (adults only) }\end{array}$ & $\begin{array}{l}19 \text { females } \\
15 \text { males }\end{array}$ & $\begin{array}{l}44 \text { females } \\
28-35 \text { males }\end{array}$ & $\begin{array}{l}21-29 \text { females }^{11} \\
25-31 \text { males }^{11}\end{array}$ \\
\hline
\end{tabular}

1) During birth season.

against higher-ranking males; and (3) male dominance rank rarely changes suddenly, being strongly dependent on group tenure (BERARD, 1990), a male's value as a Friend is approximately directly proportional to his dominance rank (CHAPAIS 1983a, 1986), at least until he has more Friends than he can effectively protect. Consistent with this hypothesis, in this study male dominance rank was a better predictor of number of Friends than group tenure (which has no direct connection to protective ability), although rank and tenure were positively correlated (see HILL, 1990 for an alternative view). Male aggression represents a major potential cost to females (SMUTS, 1985; CHAPAIS, 1986), so selection should have favored female social strategies to minimize it. Choosing a male protector involves a trade-off between two characteristics: his protective ability (ideally high) and the number of other females that he regularly protects (ideally low) [this is analogous to ORIANs' (1969) polygyny threshold model]. CHAPAIS' (1983a), Hill's (1990), and my findings that female responsibility for grooming Friends increased with increasing male dominance rank is consistent with the expectation that females will invest more in friendships from which they receive greater protection benefits. However, unlike HiLl (1990) and CHAPAIS (1983a), 
I found no tendency for females in general or non-alpha females in particular to be more responsible than males for proximity maintenance. Females may compete for the highestranking Friends, which explains why, as HILL (1990) and I found, high-ranking females tend to have higher-ranking Friends than low-ranking females.

Among savanna baboons, in contrast, variance in male protective ability is lower than in rhesus macaques [because of frequent reversals in dominance interactions, male-male coalitions, and shifting male dominance relationships (STruM, 1982; SMUTS, 1985; BerCOVITCH, 1986)], and males sometimes protect their Friends against higher-ranking males. Thus, number of other female Friends becomes the key male characteristic governing female choice of Friends, and therefore Friends are fairly evenly distributed among males, as Appendix IX in SMUTs (1985) shows.

The strong positive correlation between female age and Friends' ranks may stem from age-related differences in optimal female social investment strategies. Because male rank increases with group tenure, a young female may gain by investing in a friendship with a low-ranking male who (1) is not presently sought by many females as a Friend and (2) will stay in the group and achieve high rank and thus have high protective ability in the future. An old female, in contrast, needs a currently effective protector. In other words, a male's future value as a protector is discounted by the female as a function of her age.

Based on his findings of (1) mutual agonistic support within some heterosexual dyads and (2) a positive correlation between male dominance rank and mating success, CHAPAIS (1986) has hypothesized that males compete over periods of years to acquire central positions within a social group and mutually supportive year-round relationships with adult females. These social resources in turn enable them to experience high reproductive success, even though their mates are not necessarily the same females as their Friends. Unlike CHAPAIS, neither HILL (1990) nor I observed frequent female intervention in male-male conflicts. This difference may be a product of differences in the sizes of study groups (Table 7). CHAPAIS' (1983a, 1986) study group was somewhat smaller than HiLL's (1990) or my study groups. Male rhesus macaques usually advance in dominance rank as the males that outrank them transfer or die (KAUFMANN, 1967; SADE, 1967; VESSEY \& MeIKLE, 1987; BERARD, 1990). In a small group, a new immigrant male could attain high rank quickly following the emigration of just a few high-ranking males, whereas immigrants into a large group would, on average, have to wait longer to attain high rank. If (1) females prefer that the highest dominance ranks are held by Friends and other familiar males, and (2) female coalitional support influences males to stay in a group rather than transfer, then females would gain greater net benefits in a small group than in a large group by supporting familiar males against newcomer subordinate challengers. Because wild rhesus groups are smaller than the larger Cayo Santiago groups, CHAPAIS' (1983a, 1986) results may be more representative, in this respect, of the rhesus macaque "environment of evolutionary adaptedness"' (BowLBY, 1969) than HiLL's (1990) or my results.

Multi-year studies of Japanese macaques show that, although some dyads form friendships after sexual consort relations, they tend to avoid mating following friendship formation (TAKAHATA, 1982a, b; HufFMAN, 1991a, b). Neither my study nor those of ChaPAis $(1983 a, 1986)$ or Hill $(1987,1990)$ lasted longer than 1.5 years, so comparable data are not available for Cayo Santiago rhesus macaques. However, there is some evidence that friendship is more likely to follow than precede copulation. Specifically, in my study, the pattern of friendships was more concordant with peri-ovulatory copulation partnerships in the preceding mating season than in the following mating season. This is the result that would be expected if females become sexually avoidant of Friends over time. 
SMUTS (1985) hypothesized that this pattern of increasing female sexual aversion toward friends, as documented for Japanese macaques by TAKAHATA (1982a, b), is an artifact of provisioning and concommitant large group sizes. Specifically, TAKAHATA $(1982 \mathrm{a}, \mathrm{b})$ and HuFFMAN (1991b) report that males in small troops (15-60 individuals) transfer after 2-4 years in the troop, whereas in the provisioned and extremely well-siudied Arashiyama troop, which grew to over 260 animals, tenure of central non-natal males increased as group size increased (HUFFMAN, 1991b). Assuming that a constant number of females becomes resistant to each male's sexual advances per unit time, the more fema'es a troop contains the longer a male can stay and still experience high enough reproductive success to dissuade him from transferring (NORIKOSHI, 1976, cited in HUFFMAN, 1991b). This view implies that in Japanese macaque societies under natural conditions, female mate choice is the primary force responsible for the circulation of males between troops (HUFFMAN, 1991b). In the Arashiyama troop, because of its geographic isolation, costs of transfer were especially high, while the benefits of remaining were also unusually high because of the large number of females. In natural settings, friendships would be unlikely to persist after the female developed a sexual aversion to the male, because the male would transfer before then (SMUTS, 1985) or at the point when the costs to him of female sexual aversion exceeded the costs of intergroup transfer. No data have been published on friendships in wild rhesus macaques, but male group tenures over 36 months have not been observed (MELNICK et al., 1984), whereas some Cayo Santiago males remain in the same group for up to 16.8 years (BERARD, 1990). Whether this reflects a genuine difference between Cayo Santiago and the wild is difficult to determine, because of the possibility that it merely reflects sampling error: i.e. if the life histories of a large enough sample of wild rhesus males were known, a small percentage of them would be found to remain in one group for many years, just as a small percentage of Cayo Santiago males do.

Females might develop sexual aversions toward past mates as an adaptation to produce genetically diverse sets of offspring, or as the non-adaptive manifestation of evolved inbreeding avoidance mechanisms that equate social familiarity with genetic relatedness (Huffman, 1992; MANSON \& PERry, 1993; Small, 1993). These aversions, coupled (under some conditions) with mutual dependence of females and high-ranking males on each other for coalitional support (CHAPAIS, 1983a, 1986), lead to some predictions that could be tested using DNA fingerprinting data (BERARD et al., 1993; MARTIN et al., 1992). For instance, if females support former mates in male-male aggressive interactions, enabling them to stay in the same group and rise in rank even as their sexual attractiveness to those very females is declining, male reproductive success should correlate with highest dominance rank achieved, but most of this reproduction will occur before the male reaches his highest rank (see BERNSTEIN, 1976; SMITH, 1981). Such a result would necessitate revisions to widely accepted versions (e.g. DUNBaR, 1988: 156-181) of the hypothesis linking male dominance, resource holding power, and reproductive success.

Acknowledgements. I thank B. Gault, J. Gros-Louis, A. Lake, and S. Perry for assistance in data collection. R. Dowhan, K. Hill, W. Holmes, J. Mitani, S. Perry, B. Smuts, and Y. Takahata provided helpful comments on earlier drafts of the manuscript. M. KESSLER and J. BERARD of the Caribbean Primate Research Center gave permission to conduct this study. Research was supported by the L.S.B. Leakey Foundation, NSF (BNS-8816132), and two units of The University of Michigan: the Rackham School of Graduate Studies and the Evolution and Human Behavior Program. Cayo Santiago was supported by the University of Puerto Rico, and NIH Grant P40-RR03640-03. 


\section{REFERENCES}

Altmann, J., 1974. Observational study of behavior: sampling methods. Behaviour, 49: 227-265. Altmann, S. A., 1962. A field study of the sociobiology of rhesus monkeys (Macaca mulatta). Ann. N.Y. Acad. Sci., 102: 338-435.

Axelrod, R. \& W. D. Hamilton, 1981. The evolution of cooperation. Science, 211: 1390-1396.

Berard, J. D., 1990. Life history patterns of male rhesus macaques on Cayo Santiago. Ph.D. thesis diss., Univ. of Oregon, Oregon.

- P. Nürnberg, J. T. Epplen, \& J. Schmidtke, 1993. Male rank, reproductive behavior, and reproductive success in free-ranging rhesus macaques. Primates, 34: 481-489.

Bercovitch, F. B., 1986. Male rank and reproductive activity in savanna baboons. Int. J. Primatol., 4: $201-235$.

BeRnSTEIN, I. S., 1976. Dominance, aggression and reproduction in primate societies. J. Theor. Biol., 60: $459-472$.

Bowlby, J., 1969. Attachment and Loss. Hogarth Press, London.

Catchpole, H. R. \& G. van Wagenen, 1978. Reproduction in rhesus monkeys, Macaca mulatta. In: The Rhesus Monkey, G. H. Bourne (ed.), Academic Press, New York, pp. 118-139.

CHAPAIs, B., 1983a. Structure of the birth season relationship among adult male and female rhesus monkeys. In: Primate Social Relationships, R. A. HindE (ed.), Blackwell Scientific Publ., Oxford, pp. 200-208.

$-1983 \mathrm{~b}$. Reproductive activity in relation to male dominance and the likelihood of ovulation in rhesus monkeys. Behav. Ecol. Sociobiol., 12: 215-228.

, 1986. Why do adult male and female rhesus monkeys affiliate during the birth season? In: The Cayo Santiago Macaques, R. G. Rawlins \& M. J. Kessler (eds.), SUNY Press, Albany, New York, pp. 173-200.

Dunbar, R. I. M., 1988. Primate Social Systems. Cornell Univ. Press, Ithaca, New York.

GoRDON, T. P., 1981. Reproductive behavior in the rhesus monkey: social and endocrine variables. Amer. Zoologist, 21: 185-195.

Gouzoules, S. \& H. Gouzoules, 1987. Kinship. In: Primate Societies, B. B. Smuts, D. L. Cheney, R. M. Seyfarth, R. W. Wrangham, \& T. T. Struhsaker (eds.), Univ. of Chicago Press, Chicago, pp. $299-305$.

Halliday, T. R., 1983. The study of mate choice. In: Mate Choice, P. Bateson (ed.), Cambridge Univ. Press, Cambridge, pp. $3-32$.

HiLl, D. A., 1987. Social relationships between adult male and female rhesus macaques: I. sexual consortships. Primates, 28: 439-456.

$\longrightarrow, 1990$. Social relationships between adult male and female rhesus macaques: II. non-sexual affiliative behaviour. Primates, 31: 33-50.

Hinde, R. A. \& S. AtKInson, 1970. Assessing the roles of social partners in maintaining mutual proximity as exemplified by mother-infant relations in rhesus monkeys. Anim. Behav., 18: $169-176$.

Huffman, M. A., 1991a. Mate selection and partner preferences in female Japanese macaques. In: The Monkeys of Arashiyama: Thirty-five Years of Research in Japan and the West, L. M. Fedigan \& P. J. Asquith (eds.), SUNY Press, New York, pp. 101-121.

- 1991b. History of the Arashiyama Japanese macaques in Kyoto, Japan. In: The Monkeys of Arashiyama: Thirty-five Years of Research in Japan and the West, L. M. FEDIGAN \& P. J. AsQuith (eds.), SUNY Press, New York, pp. 21-53.

-1992 . Influences of female partner preferences on potential reproductive outcome in Japanese macaques. Folia Primatol., 59: 77-88.

Kahan, J. P. \& A. RAPOPORT, 1984. Theories of Coalition Formation. Erlbaum, Hillsdale, New Jersey.

Kaufmann, J. H., 1967. Social relationships of adult males in a free-ranging band of rhesus monkeys. In: Social Communication Among Primates, S. A. Altmann (ed.), Univ. of Chicago Press, Chicago, pp. 73-98.

MAGHSOODLOO, S., 1975. Estimates of the quantiles of Kendall's partial rank correlation coefficient. J. Stat. Comp. Simul., 4: 155-164.

\& L. Laszlo Pallos, 1981. Asymtotic behavior of Kendall's partial rank correlation coefficient and additional quantile estimates. J. Stat. Comp. Simul., 13: 41-48. 
Malik, I., P. K. Seth, \& C. H. Southwick, 1984. Population growth of free-ranging rhesus monkeys at Tughlaqabad. Amer. J. Primatol., 7: $311-321$.

Manson, J. H., 1992. Measuring female mate choice in Cayo Santiago rhesus macaques. Anim. Behav., 44: $405-416$.

, 1993. Sons of low-ranking female rhesus macaques can attain high dominance rank in their natal groups. Primates, 34: $285-288$.

\& S. E. Perry, 1993. Inbreeding avoidance in rhesus macaques: whose choice? Amer. J. Phys. Anthropol., 90: 335-344.

Martin, R. D., A. F. Dixson, \& E. J. Wickings (eds.), 1992. Paternity in Primates: Genetic Tests and Theories. Karger, Basel.

MaYnard Smith, J., 1982. Evolution and the Theory of Games. Cambridge Univ. Press, Cambridge.

Melnick, D. J., M. C. Pearl, \& A. F. Richard, 1984. Male migration and inbreeding avoidance in wild rhesus monkeys. Amer. J. Primatol., 7: 229-243.

NoË, R., 1990. A veto game played by baboons: a challenge to the use of the Prisoner's Dilemma as a paradigm for reciprocity and cooperation. Anim. Behav., 39: 78-90.

Orians, G. H., 1969. On the evolution of mating systems in birds and mammals. Amer. Naturalist, 103: $589-603$.

Ransom, T. W. \& B. S. Ransom, 1971. Adult male-infant relationships among baboons (Papio anubis). Folia Primatol., 16: 179-195.

Rawlins, R. G. \& M. J. Kessler, 1986. The history of the Cayo Santiago colony. In: The Cayo Santiago Macaques, R. G. Rawlins \& M. J. Kessler (eds.), SUNY Press, Albany, pp. $13-45$.

SADE, D. S., 1967. Determinants of dominance in a group of free-ranging rhesus monkeys. In: Social Communication Among Primates, S. A. Altmann (ed.), Univ. of Chicago Press, Chicago, pp. $99-114$.

-, B. D. Chepko-Sade, J. M. Schneider, S. S. Roberts, \& J. T. Richtsmeier, 1985. Basic Demographic Observations on Free-ranging Rhesus Monkeys, HRAF Press, New Haven, Connecticut.

Smald, M. F., 1993. Female Choices: Sexual Behavior of Female Primates. Cornell Univ. Press, Ithaca.

Smith, D. G., 1981. The association between rank and reproductive success of male rhesus monkeys. Amer. J. Primatol, 1: 83-90.

Smuts, B. B., 1985. Sex and Friendship in Baboons. Aldine, Hawthorne, New York.

- \& R. W. Smuts, 1992. Male aggression and sexual coercion of females in nonhuman primates and other mammals: evidence and theoretical implications. In: Advances in the Study of Behavior, Vol. 22, P. J. B. Slater, J. S. Rosenblatt, M. Milinski, C. T. Snowdon (eds.), Academic Press, New York, pp. 1-63.

Stolte, L. A. M., 1978. Pregnancy in the rhesus monkey. In: The Rhesus Monkey, G. H. Bourne (ed.), Academic Press, New York, pp. $171-230$.

Strum, S., 1982. Agonistic dominance in baboons: an alternative view. Int. J. Primatol, 3 : $175-202$.

TAKAHATA, Y., 1982a. Social relations between adult males and females of Japanese monkeys in the Arashiyama B troop. Primates, 23: 1-23.

- 1982b. The socio-sexual behavior of Japanese monkeys. Z. Tierpsychol., 59: 89-108.

Trivers, R. L., 1971. The evolution of reciprocal altruism. Ouart. Rev. Biol., 46: $35-57$.

VESSEY, S. H. \& D. B. MEIKLE, 1987. Factors affecting social behavior and reproductive success of male rhesus monkeys. Int. J. Primatol., 8: 281-292.

Walters, J. R. \& R. M. Seyfarth, 1987. Conflict and cooperation. In: Primate Societies, B. B. Smuts, D. L. Cheney, R. M. Seyfarth, R. W. Wrangham, \& T. T. Struhsaker (eds.), Univ. of Chicago Press, Chicago, pp. 306-317.

Author's Name and Present Address: Joseph H. Manson, Department of Anthropology, University of California, Los Angeles, 405 Hilgard Avenue, Los Angeles, California 90024-1553, U. S. A. 